\title{
A INTENCIONALIDADE NOS PARÁGRAFOS §20 A §38 DAS OBSERVAÇÕES FILOSÓFICAS DE WITTGENSTEIN
}

\author{
Aluno: Marcio Rodrigo Mello ${ }^{1}(*)$
}

\begin{abstract}
Resumo
O conceito de intencionalidade é discutido em muitas passagens das Observações Filosóficas de Wittgenstein, e aparece nesta obra como um de seus conceitos principais. A investigação do papel que este conceito desempenha nesta obra é indispensável para a compreensão do conjunto da obra de Wittgenstein, principalmente de seus últimos escritos, entre os quais estão incluídas as Investigações Filosóficas. Como forma de explicitar os termos em que este debate se estrutura inicialmente, apresenta-se aqui uma análise do conceito de intencionalidade tal qual ele aparece nos parágrafos $\$ 20$ a $\$ 38$ das Observações Filosóficas. O conceito em questão aparece com frequência no texto das Observações, mas é apresentado tematizado de maneira mais direta e sustentada a partir do parágrafo $\$ 20$, em que o autor afirma que uma a exclusão do elemento da intenção resultaria em um desmoronamento da função da própria linguagem. No decorrer dos parágrafos $\S 20$ ao $\S 38$ o debate associa a intencionalidade à análise do significado de se "ter uma expectativa" de um acontecimento. Esta análise da expectativa se mostra central na admissão da possibilidade de uma intencionalidade na linguagem, pois está vinculada à sua reflexão sobre o papel da figuração na linguagem (parágrafo $\$ 21$ e $\$ 23$ ) e sobre a relação entre o uso das palavras e sua posição dentro de determinado sistemas de proposições (parágrafos $\S 23$ e §31). Por fim, também se propõe uma análise da crítica feita a Russel pelo autor ao analisar a possibilidade da realização de uma expectativa.
\end{abstract}

A intencionalidade nos parágrafos $§ 20$ a $§ 38$ das Observações Filosóficas de

Wittgenstein

O problema da intencionalidade aparece na obra Observações Filosóficas (Philosophische Bemerkungen) de Wittgenstein primeiramente na análise sobre o que é uma expectativa e sobre a oposição do autor à concepção de Russell a respeito do mesmo tema. O termo "intencionalidade" que, no texto original em alemão se refere ao termo Intentionalität não aparece nos parágrafos analisados aqui, que fazem parte do

\footnotetext{
1 * Universidade Federal de São Paulo - UNIFESP. E-mail: marciormello@hotmail.com. Tema de Dissertação de Mestrado. Apresentado também no Workshop "Lógica e Filosofia da Linguagem" de 2014 na USP.
} 
que foi organizado pelo editor Rush Rhees como os capítulos II e III desta obra, mas o seu conceito é abordado pelo autor de forma indireta ao ser tratado pelo termo "intenção", tal como ele aparece no final do parágrafo §20: "Se você excluir da linguagem o elemento da intenção, toda a sua [da linguagem] função desmorona". A tradução aqui utilizada para o português ${ }^{2}$ traduz o termo Intention do texto organizado por Rhees em alemão como "intenção", que não pode ser confundido com o termo Absicht, utilizado em outras passagens, mas algumas vezes também traduzido como “intenção" que é usado para se falar de uma intenção ou propósito de se ir para algum lugar ou fazer alguma coisa, e pode ser classificada como um dos tipos de ações que possuem intencionalidade. Portanto, o termo alemão Intention está vinculado à ideia de Intentionalität de maneira muito mais próxima do que o termo Absicht, que é apenas uma das formas de se ter intencionalidade. A mesma é definida de maneira mais ampla como a característica da mente que se direciona a algo, ou que tem consciência de algo.

O texto das Observações Filosóficas, entregue a Russell em Maio de 1930, foi escrito com o objetivo de apresentar o trabalho intelectual desenvolvido por Wittgenstein ao Trinity College, de Cambridge com fins de renovação da bolsa de estudos do autor. O material organizado por ele era uma reunião de suas anotações de cerca de um ano, no qual ele havia tentado resolver alguns problemas da sua primeira obra, o Tractatus Logico-Philosophicus (de agora em diante somente Tractatus). No entanto, não era um texto voltado para a publicação, mas expressava suas ideias, na época.

O terceiro capítulo das Observações Filosóficas (a partir daqui chamada somente de Observações), formada pelos parágrafos $\$ 20$ a $\$ 38$, tem início com dois alertas: em primeiro lugar Wittgenstein afirma que uma concepção errônea sobre o funcionamento da linguagem pode "destruir" toda a lógica da linguagem, ou seja, pode resultar em contra sensos, quando esta é aplicada nos usos cotidianos da linguagem. O autor se propõe desfazer equívocos resultantes de tais concepções através da observação da maneira como a linguagem realmente funciona. O segundo alerta é o de que não se deve excluir da linguagem o elemento da intenção (Intention). Sendo assim, poderia se supor que o autor sustenta uma concepção intencional sobre a linguagem, porém é exatamente esse tipo de concepção que é vítima das críticas desferidas pelo autor. No

\footnotetext{
${ }^{2}$ Da editora Loyola, 2005.
} 
início do parágrafo $\$ 21$ estas críticas já aparecem, na tentativa de desfazer os equívocos resultantes de um mau entendimento da linguagem. $\mathrm{O}$ alvo prioritário das críticas é a concepção de Russell, desenvolvida na obra Analysis of Mind. O texto será deste capítulo foi construído como uma contraposição à concepção de Russell, a apresentação de outra concepção e sua fundamentação no funcionamento da linguagem.

Segundo Wittgenstein, para Russel, um pensamento é verdadeiro quando existe um pensamento, o fato e uma espécie de "reconhecimento", ou seja, o critério de verdade de uma proposição aparece aqui como um tipo de sentimento de satisfação quando alguém acredita, espera ou deseja algo e se sente satisfeito quando algum evento satisfaz este seu desejo, crença ou expectativa. A expectativa, particularmente, é um dos exemplos mais usados no texto para se empreender uma análise sobre a intencionalidade, pois, o que significa possuir uma expectativa? No cotidiano, as pessoas esperam uma infinidade de coisas o tempo todo: poder andar, que o chão esteja sólido, que as coisas caiam no chão quando são derrubadas, etc. Mas, mais do que isso, a pergunta é? "Onde” começa a expectativa? Na mente? É ela uma representação da realidade que é confirmada pela nossa visão do fato esperado? Segundo o Tractatus, uma proposição é uma figuração, ou seja, uma representação de um fato, que é tornada possível porque tanto linguagem quanto a realidade possuem a mesma "forma lógica". No entanto, Wittgenstein abandona a ideia de "forma lógica" na revisão da sua obra em 1930, portanto, o que poderia levar a uma conexão entre linguagem e mundo? Para Russell, tal conexão dada através de um tipo de reconhecimento apresenta diversos problemas, que são apresentados por Wittgenstein a partir do parágrafo §22. Aqui, o exemplo para ilustrar a realização de uma expectativa é o da fome: Segundo Russell, se alguém tem o desejo de comer uma maçã e leva um soco no estômago, que tira a sua fome, então era esse soco que a pessoa queria, originalmente. Este exemplo elaborado pelo autor mostra que a confirmação de uma expectativa não deve depender de um tipo de reconhecimento ou de um tipo de "sensação de satisfação", pois não pode ser um critério de verdade de uma proposição alguém ficar satisfeito com determinado fato, e tal exemplo do "soco no estômago" serve para mostrar o quão absurdo é o resultado da aplicação de tal concepção. Poderia se ilustrar a concepção de Russell com outro exemplo, usado por Wittgenstein no texto das Observações: Alguém tem a expectativa de ver a mesma cor que ela viu ontem, e então ela vê uma mancha vermelha e diz: "isto é o que eu esperava". Alguém tem uma expectativa de ver uma determinada cor, 
imagina essa cor, vê uma mancha vermelha, compara-a com a cor vermelha que possui no pensamento e sente-se "satisfeita" com aquela cor ou "reconhece-a". No entanto esta descrição da expectativa já é problematizada anteriormente no parágrafo §11, no qual Wittgenstein diz que, a expectativa de conseguir reconhecer uma cor: o vermelho, por exemplo, em determinada situação descrita neste parágrafo, tem como pressuposto a ideia de que temos um tipo de "paradigma" na memória, com o qual comparamos um determinado evento, como por exemplo: ver uma mancha vermelha ou um modelo de vermelho em um catálogo de cores. Existem dois problemas neste tipo de concepção: o vermelho que alguém poderia imaginar é o mesmo que o vermelho que a pessoa poderia estar vendo, como Wittgenstein afirma no $§ 12$ ? E de quais critérios poderia se falar para que fosse possível dizer se se consegue ter sucesso ou fracasso em reconhecer a cor que se tinha unicamente na memória? Segundo os parágrafos $\S 11$ e $\S 16$, a afirmação do sujeito que diz: "esta é a cor que eu esperava ver" ou "isto é o que eu esperava" não pode ser falsificada, pois o único critério que o sujeito possuía era a sua própria lembrança. A consequência imediata deste exemplo é que se poderia também imaginar alguém que procura uma cor que nunca outras pessoas viram, mas da qual ela tem uma lembrança, e que em determinado momento, em um cômodo de uma casa aponta para uma mancha na parede e diz que esta "é a cor que ela procurava". Uma afirmação como esta: "Isto é o que eu esperava", ou "isto é o que eu procurava" aparentemente não pode ser verdadeira e nem falsa, pois não se teria meios de falsificá-la, e talvez tampouco o próprio sujeito, admitindo-se a concepção de Russell.

A concepção atribuída a Russel de intenção liga-se a uma tradição de uma concepção de significado na qual o significado de uma palavra ou nome é o objeto ou evento para o qual ele "aponta", ou seja, para o objeto ou evento que ele "denota". O próprio Wittgenstein, de certa forma, sustentou uma concepção intencional semelhante ao conectar nomes e objetos, proposições e fatos no Tractatus, abandonada na elaboração das Observações. Por isso a concepção figurativa da intenção citada no parágrafo $\$ 21$ não é a mesma que aparece no Tractatus. A sua primeira concepção de figuração, admitida de maneira semelhante por Russell é problematizada no parágrafo $\S 12$, onde se localizam as críticas mais severas a este conceito de "intencionalidade". A crítica de Wittgenstein se dirige á concepção que sustenta que alguém "imagina" o significado de uma palavra quando a ouve. Esta concepção, chamada por ele de "ingênua" sofre com a mesma dificuldade que já foi citada: Ao se imaginar uma cor, 
não se tem critérios para compará-la com a própria cor, pois a cor que se imagina não é a mesma cor que se vê. Esta concepção parte da pressuposição de que a mente possui um tipo de "imagem" da cor vermelha, com a qual se compara o modelo na realidade. E é este tipo de concepção que Russell sustenta: que afirma uma possibilidade de se afirmar a verdade de um pensamento ou proposição através deste reconhecimento ou sentimento de satisfação e de "comparação" do evento representado com a representação no pensamento, que segundo Wittgenstein, é uma relação externa, já que depende de um "terceiro evento" que nada tem a ver com o pensamento e com o evento acontecido. Segundo o autor, no parágrafo $\$ 25$, isso equivale a dizer que, se alguém tem uma expectativa $p$ e espera um tipo de satisfação da sua expectativa, ela espera algo diferente da própria expectativa $p$, e não a própria realização do evento. E se fosse possível fundamentar os critérios de verdade em um evento diferente do próprio evento que realize tal expectativa, como se, segundo a concepção de Russell seria necessário um reconhecimento para dizer que "isto é aquilo que se esperava", também seria necessário reconhecer que se conseguiu reconhecer uma determinada cor, por exemplo, e assim regredindo ao infinito. Desta forma, segundo as críticas de Wittgenstein, tal posição a respeito da característica intencional da linguagem não se sustenta quando aplicada à maneira como a linguagem é usada no cotidiano, ou seja, da maneira como ela realmente funciona.

A concepção de Wittgenstein do significado de se ter uma expectativa vincula-se com o que ele chamou de uma relação interna entre fala e ação, que é anterior a qualquer tipo de relação externa atribuída à expectativa e, como já havia dito no parágrafo $\S 21$, o autor admite apenas o pensamento e o fato, ou seja, a expectativa e o evento que a substitui. Portanto, tal conexão entre expectativa e realidade fundamentase no modo como o evento responde a expectativa, substituindo-a. Dessa forma, é um contra senso alguém perguntar se "isto era realmente aquilo que eu esperava?" Isso porque a expectativa é definida em termos do evento que responde a ela, e não o contrário: não é o evento que é definido através de seu confronto com a expectativa como o confronto com um tipo de paradigma, mas, segundo o que o autor afirma no parágrafo $\$ 29$, a expectativa é definida nos termos em tudo aquilo que a substitui, ou seja, em todos os eventos que a substituem. No entanto, esta concepção não parece admitir uma intencionalidade para à linguagem, mas sim uma extensionalidade, já que a expectativa passa a ser definida por todas as situações que a substituem, como por 
exemplo: Alguém espera a chegada de um amigo em sua casa no período da tarde. Existem centenas de situações que poderiam preencher tal expectativa: $\mathrm{O}$ amigo poderia chegas às 13 horas, às 13 horas e um minuto ou 13 horas e dois minutos da tarde, e assim sucessivamente, ou poderia chegar alegre ou triste, cansado ou disposto, ou poderia chegar com ou tipo de roupa, ou outro, etc. Todos estes casos constituiriam o preenchimento de tal expectativa, e também a definiriam. Sendo assim, é o conjunto de eventos que define a própria expectativa.

É também necessário notar a importância de falarmos sobre um "preenchimento" de uma expectativa, como tradução para o termo Erfullüng, do alemão. Este termo, traduzido para o inglês nas Philosophical Remarks como Fulfilment se refere de maneira muito mais precisa à ideia de um preenchimento de uma expectativa, tal como a comparação da mesma como a forma vazia de um corpo a ser preenchida pela sua forma sólida. O termo "realização" como tradução de Fulfilment e de Erfullüng não se aplica de maneira mais precisa ao termo por remeter à realização de um modelo que já se encontrava no pensamento, podendo ser entendida, de modo enganoso, essa "realização" como adequação ao modelo que já se encontrava no pensamento, e não o contrário.

A concepção de expectativa e, por conseguinte, sua relação com a intenção na linguagem encontra-se vinculada com a descrição do significado como uso, iniciada por Wittgenstein no texto das Observações. O significado de uma palavra é definido desde o início das Observações de modo extensional, ou seja, voltando-nos para o parágrafo $\S 12$, podemos notar que o autor afirma que uma palavra só tem significado no contexto de uma proposição, e que de maneira mais precisa, no parágrafo §28: (cito) “o sentido de uma proposição pressupõe o uso gramaticalmente correto de certas palavras"3. Assim sendo, o significado de uma palavra não é definido de maneira "intencional”, no sentido tradicional do termo, tal como ele é aplicado por Russell, mas através dos usos corretos das palavras dentro dos seus contextos, ou seja, como membro de um sistema de proposições $^{4}$. Quando alguém pergunta pelo significado de uma palavra o que se deve fazer é descrever seus usos nas proposições, pois não se trata mais de se falar de uma mesma forma lógica entre linguagem e mundo, à maneira do Tractatus. Nesta concepção só podemos falar sobre o mundo com a linguagem em seus usos que

\footnotetext{
${ }^{3}$ Ludwig WITTGENSTEIN. Observações Filosóficas. p. 52

${ }^{4}$ Id. Ibid. p. 44
} 
possuam a mesma multiplicidade que o evento descrito, mas não podemos falar de uma conexão lógica entre linguagem e mundo. O que possuímos são os usos cotidianos das palavras e as diferentes "classes de linguagens" e suas diferentes gramáticas.

Wittgenstein inicia o texto das Observações usando o termo "Gramática" em um eixo principal de sua análise sobre o significado na linguagem. Ele afirma que o esclarecimento da gramática é necessário para poder se analisar a proposição de modo completo. Atribuindo importância maior para a gramática, o autor afirma que se trata da "nossa" gramática, ou seja, dos usos "cotidianos" e da linguagem "tal como ela se apresenta”, e não de uma linguagem ideal, como ele afirma no parágrafo §3. É através de uma visão perspícua sobre a Gramática, de uma visão "panorâmica", buscando separar aquilo que é essencial daquilo que não é essencial na nossa linguagem, objetivo proposto no parágrafo $§ 1$. Aqui também é apresentado o método: descrever "classes de linguagens", ou seja, tipos de linguagens e seus usos, fazendo comparações entre diferentes tipos de representações linguísticas que possuam a mesma multiplicidade, e excluindo tudo aquilo que não é essencial. Pode se usar o exemplo semelhante aos exemplos dos parágrafos $\S 10$ e $§ 20$ : Descrever um objeto como, por exemplo, “o livro vermelho". É possível, além desta representação linguística, se apresentar outra, como o desenho do livro pintado de vermelho, ou separar o livro vermelho dos livros de outras cores, ou dizer que o livro "não é azul", "não é amarelo" e assim sucessivamente, até chegar ao livro vermelho, etc. No entanto, a diferença é que aqui se descreve usos de palavras e formas de representação de um evento que só possuem sentido quando usados em contextos que possuam a mesma multiplicidade que a sua representação. Não faz sentido dizer que, para se encontrar o livro, deve-se "ouvir o som do vermelho". Não é assim que essa palavra é usada.

Apesar da defesa de uma concepção extensional da expectativa e do funcionamento da linguagem, Wittgesntein oscila entre esta e outra concepção aparentemente oposta, na qual admite uma "intenção" (aqui traduzida do termo Absicht) ou "propósito" (derivada do termo Absicht) no funcionamento da linguagem. Nos parágrafos $\S 13$ e $\S 31$ Wittgenstein compara a linguagem a um "painel de controle", e as palavras como "alavancas". Assim como existem diferentes tipos de alavancas com funções diferentes em uma sala de controle, assim as palavras operam na linguagem. $\mathrm{Na}$ comparação como alavancas, pode-se ver que algumas delas funcionam quando 
movimentadas de modo contínuo, como uma manivela, enquanto outras só possuem uma função de "ligado" e outra de "desligado", e outra ainda acelera a máquina na medida em que é empurrada para frente, etc. E de forma semelhante algumas palavras funcionam de determinada maneira em determinado contexto, e não em outros. Ou podem funcionar de modos diferentes em diferentes contextos, quando, por exemplo, fazemos uma descrição "Ele está na frente de uma parede vermelha" ou "este tomate não está tão vermelho". Segundo os parágrafos $\S 3$ e $\S 8$, uma palavra pode ter o papel de uma "variável" na proposição, quando podemos substituir, na instrução: "pegue aquele livro vermelho" por outra palavra como, por exemplo, azul, amarelo ou verde no lugar do termo "vermelho". Porém, ainda no parágrafo $§ 31$ também afirma que o propósito de uma alavanca não pode ser descoberto somente a partir dela mesma, mas através do propósito que há no uso da mesma. Da mesma forma, o exemplo do autor no parágrafo $\S 15$ pode ilustrar essa ideia: Uma caixa de câmbio quebrada poderia ter quatro posições diferentes, mas foi quebrada antes do seu uso. No entanto eram possíveis as quatro posições, e seu propósito é dado "pelo uso que se intentou (Absicht) dar a ela" forma o autor deixa margem a uma possibilidade de intencionalidade da linguagem nestes aspectos, sustentada na afirmação de que a linguagem é como uma sala de controle construída segundo um determinado "propósito"6. E como ele também afirma que se ter uma expectativa está ligado a se "procurar"7 algo, e que esse algo que se procura deve estar no mesmo "espaço" ${ }^{8}$ da expectativa, ou seja, no mesmo contexto. Portanto Wittgenstein não exclui o papel do pensamento como representação da realidade, como ele afirma no parágrafo $\S 38$ que "as nossas palavras adquirem sentido a partir do fato que refletem de modo mais ou menos perfeito as operações das imagens [figurações]"9. Pois do contrário, como se poderia ter uma expectativa de algo que, provavelmente, nunca acontecerá, como, por exemplo, ganhar na loteria ou se aprender algum instrumento musical? E no caso em que uma pessoa que espera "o fim do mundo"? Podem, neste sentido, existir expectativas que nunca poderiam ser preenchidas, mas há a necessidade de um substituto para tal evento, e são as representações ou figurações que possuem a mesma multiplicidade com a realidade. Uma expectativa pressupõe a possibilidade intencional de se aplicar determinado

\footnotetext{
${ }^{5}$ Id. Ibid. p. 54

${ }^{6}$ Id. Ibid. p. 54

${ }^{7}$ Id. Ibid. p. 52,55 e 56

${ }^{8}$ Id. Ibid. p. 53 e 55

${ }^{9}$ Id. Ibid. p. 57
} 
"padrão de medida" à realidade, em processos de representação da mesma que possam ter a mesma multiplicidade que o fato. Pois só se pode medir a altura de alguém com uma fita métrica, e não com uma máquina de pesar. Sendo assim, o padrão de medida da expectativa deve se submeter a determinados contextos de uso, e é determinado por eles. Da mesma forma uma expectativa é determinado pelos eventos que a substituem e as palavras são determinadas pelos seus contextos de uso na linguagem. Pode se concluir daí que Wittgenstein, apesar de sustentar aspectos intencionais da linguagem, como o propósito dos usos das palavras e a aplicação de padrões de medida no preenchimento de tais explicações, localiza o fundamento destes aspectos intencionais em bases extensionais, buscando uma conciliação destas duas concepções. Nota-se aqui a característica do processo de construção de mudança das Observações, que retrata de maneira significativa o momento de autocrítica e reconstrução pelo qual o autor passava na época, e que em muitas obras destaca-se como característica de seu objetivo de constante aperfeiçoamento de sua análise da linguagem.

\section{Bibliografia}

ENGELMANN, Mauro Luiz. Wittgenstein's Philosophical Development: phenomenology, gramar, method, and the anthropological view. London: Palgrave Macmillan, 2013.

MALCOM, Norman. Wittgenstein's Philosophische Bemerkungen in The Philosophical Review Vol 76, n.2 (Abril de 1967), p. 220-229.

MEDINA, José. The Unity of Wittgenstein's Philosophy: Necessity, Intelligibility, and Normativity. Albany: State University of New York, 2002.

RUSSELL, Bertrand. The Analysis of Mind. New York: Macmillan Company, 1922.

SEARLE, John. Intencionalidade. São Paulo: Martins Fontes, 2001.

WITTGENSTEIN, Ludwig. Observações Filosóficas. São Paulo: Loyola, 2005. . Philosophical Remarks. Oxford: Blackwell, 1984. . Philosophische Bemerkungen. Frankfurt: Suhrkamp, 1984. Some Remarks on Logical Form in Knowledge, Experience

and Realism, Supplementary Volumes, Vol. 9, p. 162-171. Blackwell Publishing on behalf of The Aristotelian Society, 1929. 